\title{
EXTRACTION OF AMINE BY W/O/W EMULSION SYSTEM
}

\author{
MASAAKI TERAMOTO, HIROSHI TAKIHANA, \\ MichIRU SHIBUTANI, TAKAHIRO YUASA, \\ YoshiKazU MIYAKE AND HIROSHI TERANISHI \\ Department of Industrial Chemistry, Faculty of Industrial Arts, \\ Kyoto Institute of Technology, Matsugasaki, Kyoto 606
}

\begin{abstract}
A mass transfer model for the extraction of amine in $\mathrm{W} / \mathrm{O} / \mathrm{W}$ emulsion systems having internal aqueous $\mathrm{HCl}$ solution phase is presented which takes into account the diffusion in $W / O$ emulsion drops as well as the external mass transfer around W/O emulsion drops, and the effect of various parameters on the extraction rate is clarified. Experimental data on the extraction of aniline, $p$ and $m$-toluidine by $\mathrm{W} / \mathrm{O} / \mathrm{W}$ emulsion systems using a batch-type agitation vessel is discussed on the basis of the present model. It is found that the model can explain the tendency of the experimental data. The mass transfer mechanism in $W / O$ emulsion drops is discussed on the basis of the experimentally evaluated value of effective diffusivity in W/O emulsion drops.
\end{abstract}

\section{Introduction}

Separation processes using liquid surfactant membranes, first developed by $\mathrm{Li}^{6}$, have been noted as a novel technique which can be used for the separation of hydrocarbons, the treatment of wastewater containing such contaminants as phenol and amine, and the recovery of heavy metals from acidic leach liquor. To establish the liquid surfactant membrane technique as a practical process, it is important to elucidate the permeation mechanism through the membrane. The mechanism of permeation without a carrier differs from that with a carrier, and the former is much simpler than the latter. However, very few papers have been presented on the permeation mechanism even for the case of physical permeation. Casamatta et al..$^{3)}$ analyzed the simplest case, i.e., the permeation of hydrocarbons in $\mathrm{O} / \mathrm{W} / \mathrm{O}$ emulsion system without chemical reaction.

A typical example of a more complicated case of practical importance where chemical reaction occurs in internal aqueous-phase drops and no carrier is contained in the membranes is the removal of phenol in a $\mathrm{W} / \mathrm{O} / \mathrm{W}$ emulsion which consists of an external aqueous phase containing phenol (phase I), internal aqueous phase droplets containing $\mathrm{NaOH}$ (phase III) and oil-phase membranes (phase II) separating the two aqueous phases as shown in Fig. 1. However, no paper on the permeation mechanism is available except a very simplified model by Cahn and $\mathrm{Li}^{11}$. As will be shown later, the mechanism of the extraction

\footnotetext{
Received September 5, 1980. Correspondence concerning this article should be addressed to $\mathrm{M}$. Teramoto.
}

of amine by a W/O/W system with an internal aqueous phase containing $\mathrm{HCl}$ is the same as that of the extraction of phenol. In the present paper the experimental results for the extraction of amine, obtained using a batch-type agitation vessel, are discussed on the basis of a theoretical analysis which takes into account the mass transfer around the $\mathrm{W} / \mathrm{O}$ emulsion drops as well as the diffusion in the W/O emulsion drops.

\section{Theory}

\subsection{Chemical equilibrium}

When amine dissolves in an aqueous solution of $\mathrm{HCl}$, i.e., in phase III, the following equations hold.

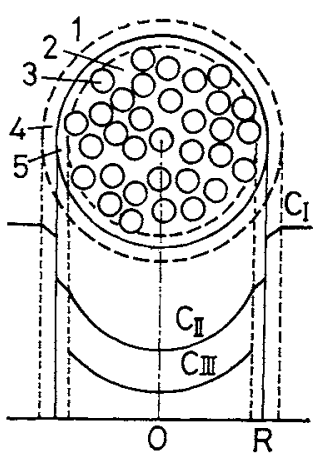

1: External aqueous phase (phase I)

2: Oil membrane phase (phase II)

3: Internal aqueous phase (phase III)

4: Film of phase $I$ around W/O emulsion drop

5: Peripheral oil layer in $\mathrm{W} / \mathrm{O}$ emulsion

Fig. 1 Schematic diagram of $\mathrm{W} / \mathrm{O} / \mathrm{W}$ emulsion system 


$$
\begin{gathered}
K_{a}=\left[\mathrm{RNH}_{2}\right]\left[\mathrm{H}^{+}\right] /\left[\mathrm{RNH}_{3}^{+}\right]=C\left[\mathrm{H}^{+}\right] / P \\
K_{w}=\left[\mathrm{H}^{+}\right]\left[\mathrm{OH}^{-}\right]
\end{gathered}
$$

$\left[\mathrm{RNH}_{3}{ }^{+}\right]+\left[\mathrm{H}^{+}\right]=\left[\mathrm{Cl}^{-}\right]+\left[\mathrm{OH}^{-}\right]$,

$$
\left(P+\left[\mathrm{H}^{+}\right]=A+\left[\mathrm{OH}^{-}\right]\right)
$$

$$
\left[\mathrm{RNH}_{2}\right]_{\mathrm{T}}=\left[\mathrm{RNH}_{2}\right]+\left[\mathrm{RNH}_{3}{ }^{+}\right],(T=C+P)
$$

If $\left[\mathrm{OH}^{-}\right] \ll\left[\mathrm{Cl}^{-}\right]$, then the following equation is derived from Eqs. (1)-(4).

$$
T=C\left(C+A+K_{a}\right) /\left(C+K_{a}\right)
$$

The above equation is simplified as follows.

$$
\begin{array}{lll}
\text { region (a): } & T=C A / K_{a} & \left(C \ll K_{a} \ll A\right) \\
\text { region (b): } & T=A & \left(K_{a} \ll C \ll A\right) \\
\text { region (c): } & T=C & \left(C \gg K_{a}, A\right)
\end{array}
$$

Figure 2 shows Eqs. (5) and (6) graphically. In the regions of (a) and (b) this curve is similar to Langmuir's adsorption isotherm. In the same figure is shown the relation of $T / C$ vs. $C$ which corresponds to the ratio of the total solubility of amine in the presence of $\mathrm{HCl}$ to that without $\mathrm{HCl}$. The value of $T / C$ is very large and almost constant $\left(=A / K_{a}\right)$ in region (a), inversely proportional to $C$ in region (b), and approaches unity in region (c).

\section{2 Development of model}

The following assumptions are made to analyze the extraction rate of amine.

(1) The diffusion rate of amine in W/O emulsion drops is expressed by Eq. (7) using an effective diffusivity.

$$
N=-D_{e}\left(\partial C_{\mathrm{II}} / \partial r\right)
$$

(2) The diameter of W/O emulsion drops is uniform. (3) In phase III, chemical equilibrium is attained instantaneously. (4) The mass transfer rate of amine from phase II to III is expressed by the second term of the right-hand side of Eq. (9). These assumptions lead to the following basic equations (see Fig. 1).

$$
\begin{aligned}
& -\left(1-\phi^{\prime}\right) d C_{\mathrm{r}} / d t=K_{0} a_{0}\left\{C_{\mathrm{I}}-\left(C_{\mathrm{TI}} / K\right)_{r=R}\right\} \\
& (1-\phi) \partial C_{I I} / \partial t=\left(D_{e} / r^{2}\right) \partial\left(r^{2} \partial C_{I I} / \partial r\right) / \partial r \\
& -K_{i} a_{i}\left(C_{\mathrm{II}}-K C_{\mathrm{III}}\right) \\
& \phi\left(d T_{I I I} / d C_{I I I}\right) \partial C_{I I I} / \partial t=K_{i} a_{i}\left(C_{I I}-K C_{I I I}\right) \\
& \text { I.C.; } C_{\mathrm{I}}=C_{\mathrm{I}, 0}, C_{\mathrm{II}}=C_{\mathrm{III}}=0(0 \leqq r \leqq R) \text { for } t=0 \\
& \text { B.C. } 1 ; \partial C_{\mathrm{II}} / \partial r=0 \text { for } r=0, t>0 \\
& \text { B.C. } 2 ; D_{e}\left(\partial C_{I I} / \partial r\right)=K_{0}\left\{C_{I}-\left(C_{I I} / K\right)_{r=R}\right\} \\
& \text { for } r=R, t>0
\end{aligned}
$$

The dimensionless forms of the above equations are

$$
\begin{gathered}
\partial y_{\mathrm{I}} / \partial \theta=-\left\{3 \phi^{\prime} B i /\left(1-\phi^{\prime}\right)\right\}\left\{y_{\mathrm{I}}-\left(y_{\mathrm{II}}\right)_{x=1}\right\} \\
\partial y_{\mathrm{II}} / \partial \theta=\left[\partial^{2} y_{\mathrm{II}} / \partial x^{2}+(2 / x)\left(\partial y_{\mathrm{II}} / \partial x\right)\right. \\
\left.-\phi m\left(y_{\mathrm{II}}-y_{\mathrm{III}}\right)\right] /(1-\phi) \\
\partial y_{\mathrm{III}} / \partial \theta=\left(K m / g\left(y_{\mathrm{III}}\right)\right)\left(y_{\mathrm{II}}-y_{\mathrm{III}}\right) \\
\text { I.C. } ; y_{\mathrm{I}}=1, y_{\mathrm{II}}=y_{\mathrm{III}}=0(0 \leqq x \leqq 1) \text { for } \theta=0 \\
\text { B.C. } 1 ; \partial y_{\mathrm{II}} / \partial x=0 \text { for } x=0, \theta>0
\end{gathered}
$$

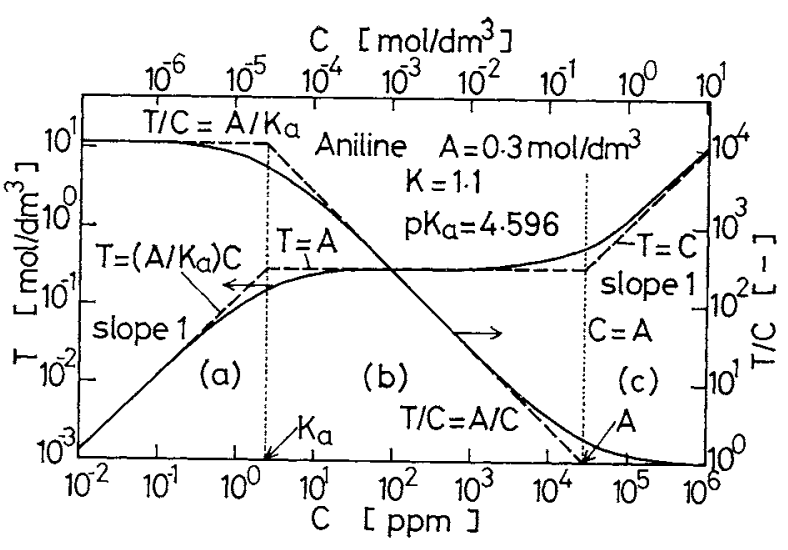

Fig. 2 Chemical equilibrium of aniline-HCl system

$$
\text { B.C. } 2 ; \partial y_{\mathrm{II}} / \partial x=(B i / K)\left\{y_{\mathrm{I}}-\left(y_{\mathrm{II}}\right)_{x=1}\right\} \text { for } x=1, \theta>0
$$

where

$$
g\left(y_{I I}\right)=d T_{I I I} / d C_{I I I}=1+\alpha \beta /\left(y_{I I I}+\alpha\right)^{2}
$$

The basic equations can be numerically solved if seven parameters $\phi, \phi^{\prime}, K, \alpha=K_{a} / C_{\mathrm{I}, 0}, \beta=A / C_{\mathrm{I}, 0}$ $B i=K_{o} R / D_{e}$ and $m=3 K_{i} R^{2} / D_{e} R_{i}$ are given. The values of $K_{a}$ are available ${ }^{5}$, the partition coefficient $K$ can be experimentally determined and $\phi, \phi^{\prime}, \alpha$ and $\beta$ are specified by the experimental condition. The last two parameters are difficult to evaluate because data on $K_{o}, K_{i}$ and $D_{e}$ are not available. However, if $m$ is sufficiently large, phase III is considered to be in equilibrium with phase II. The term "equilibrium" means that $C_{\mathrm{II}}$ is related to $C_{\mathrm{III}}$ as follows.

$$
C_{\mathrm{II}}=K C_{\mathrm{III}}
$$

Thus, in the case of $m=\infty$, Eqs. (15) and (16) are combined to give Eq. (22).

$$
\frac{\partial y_{I I}}{\partial \theta}=\frac{1}{1-\phi+(\phi / K) g\left(y_{I I}\right)}\left(\frac{\partial^{2} y_{I I}}{\partial x^{2}}+\frac{2}{x} \frac{\partial y_{I I}}{\partial x}\right)
$$

As will be explained later, when $m$ is sufficiently large, the $y_{I}$ vs. $\theta$ relation obtained from Eqs. (8)-(10) can be closely approximated by that from Eqs. (8) and (22). In this case, the value of $B i$ can be estimated as follows. (1) As shown in Fig. 7, experimental data with different initial concentrations of amine are plotted as $y_{\mathrm{I}}$ vs. $\log t$ (chart 1). (2) Numerical solutions of Eqs. (8) and (22) are plotted as $y_{x}$ vs. $\log \theta$ for specified values of parameters $\phi, \phi^{\prime}, K, \alpha$ and $\beta$ corresponding to the experimental condition with $B i$ as a parameter (chart 2). A typical example is shown in Fig. 5. Here it should be noted that $C_{1,0}$ is related to parameters $\alpha$ and $\beta$. (3) Find the value of $B i$ which can give the best agreement between these two relations by fitting these two charts as shown in Fig. 7 . By this procedure, $t_{\theta=1}$, the real time corresponding to $\theta=1$, can be determined. Then $D_{e}$ and $K_{0}$ are calculated as follows. 


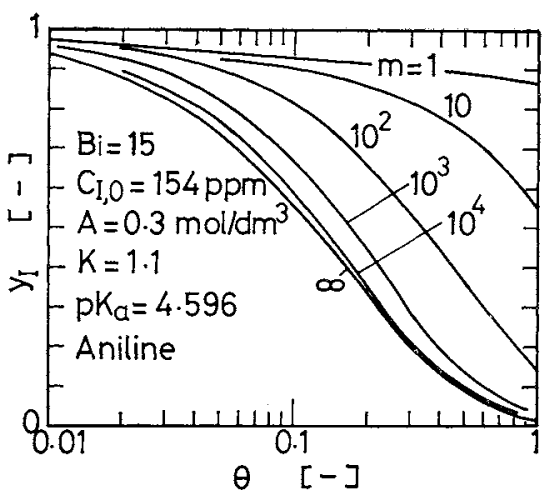

Fig. 3 Effect of $m$ on extraction rate $(\phi=0.5$, $\phi^{\prime}=\mathbf{0 . 1 3 3}$

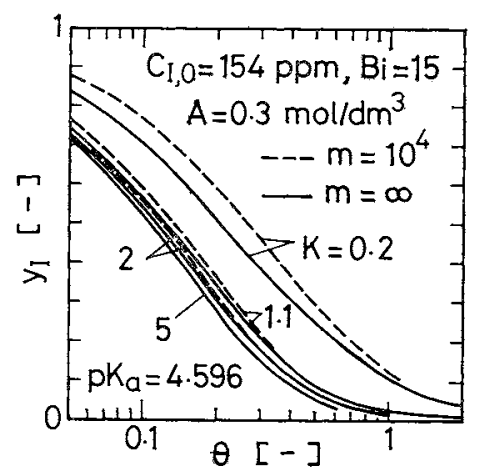

Fig. 4 Effect of $K$ on extraction rate $(\phi=0.5$, $\phi^{\prime}=\mathbf{0 . 1 3 3 )}$

$$
\begin{gathered}
D_{e}=R^{2} / t_{\theta=1} \\
K_{o}=B i D_{e} / R=B i R / t_{\theta=1}
\end{gathered}
$$

When $m$ is not so large, the determination of $B i$ may be difficult because it is also difficult to estimate the value of $m$ which includes $K_{i}, D_{\theta}$ and $R_{i}$.

As $\theta$ increases, equilibrium is attained among phases I, II and III. The equilibrium concentration is calculated from Eqs. (25) and (26) which are derived from material balance, chemical and phase equilibrium equations.

$$
\begin{aligned}
& y_{\mathrm{I}, \infty}=y_{\mathrm{II}, \infty}=y_{\mathrm{III}, \infty}=\left(-b+\sqrt{b^{2}-4 a c}\right) / 2 a \\
& a=1-\phi^{\prime}+\phi \phi^{\prime}+K \phi^{\prime}(1-\phi) \\
& b=\phi^{\prime}[\phi \beta+\alpha\{\phi+K(1-\phi)\}]-\left(1-\phi^{\prime}\right)(1-\alpha) \\
& c=-\left(1-\phi^{\prime}\right)
\end{aligned}
$$

This is the lowest attainable concentration in phase I when the extraction is carried out ideally.

It should be noted that Eqs. (5), (6), (8)-(24) can be applicable to the extraction of weak acids such as phenol, cresol and xylenol in $\mathrm{W} / \mathrm{O} / \mathrm{W}$ emulsion systems containing an internal aqueous phase of $\mathrm{NaOH}$ solution if $K_{a}$ is substituted by $K_{w} / K_{a}$ in these equations and $A$ is defined as the initial concentration of $\mathrm{NaOH}$.

\section{3 Numerical solution}

The basic equations were solved numerically by

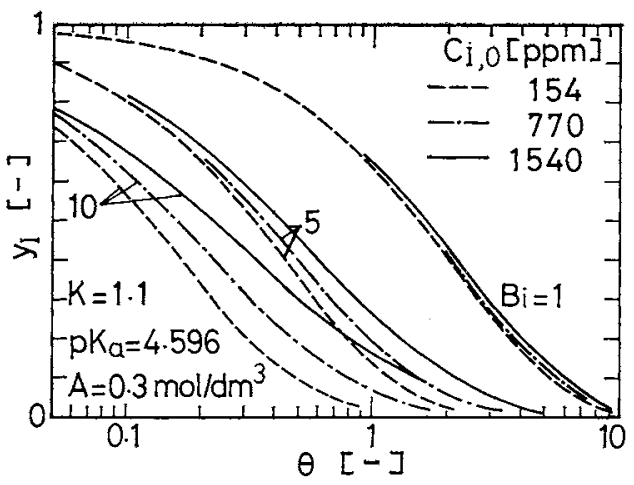

Fig. 5 Effect of $B i$ and $C_{\mathrm{I}, 0}$ on $y_{\mathrm{I}}$ vs. $\theta$ relation (aniline, $\phi=0.5, \phi^{\prime}=0.133$ )

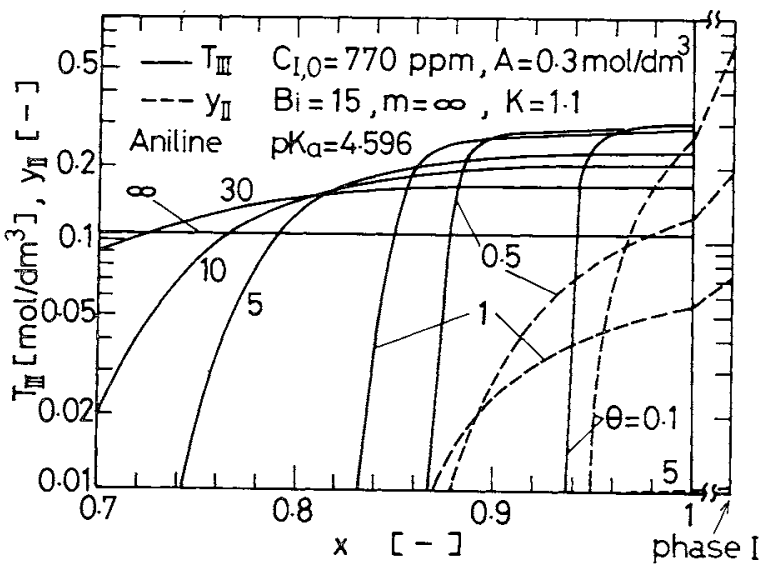

Fig. 6 Computed concentration profiles in W/O emulsion drop (aniline, $m=\infty, \phi=0.5, \phi^{\prime}=0.133$ )

means of a finite difference method. Figure 3 shows the effect of $m$ on the $y_{\mathrm{I}}$ vs. $\theta$ relations, which indicates that the relation approaches that for $m=\infty$ as $m$ becomes large, and that the solution for $m=10000$ can be approximated by that for $m=\infty$. However, it should be noted that this does not necessarily mean that phase III is completely in equilibrium with phase II. Equilibrium is attained when $m$ is much larger. As shown in Fig. 4, when $K$ is larger, the curve for $m=10000$ is approximated by that for $m=\infty$ more closely because the ratio of diffusional resistance in W/O emulsion drops to that between phase I and $\mathrm{W} / \mathrm{O}$ emulsion drops becomes smaller. The same situation is encountered when $B i$ is small. It was also found that when $C_{\mathrm{I}, 0}$ is high, the equilibrium between phases II and III is attained at smaller value of $m$. This is explained as follows. As shown in Fig. 2, the higher the amine concentration, the lower is $T / C$, which means that the transfer of a small amount of amine from phase II to III is sufficient to equilibrate the two phases. Figure 5 shows how the effect of $C_{\mathrm{I}, 0}$ on $y_{\mathrm{r}}$ varies depending on $B i$. When $B i$ is small, the $y_{I}$ vs. $\theta$ curve is steep and the effect of $C_{I, 0}$ on the $y_{\mathrm{I}}$ vs. $\theta$ relation is small. These characteristics are used to determine $B i$ from the experimental data. 
Typical concentration profiles in a W/O emulsion drop are shown in Fig. 6 where $y_{\mathrm{I}}$ is also shown on the right ordinate. It is clearly shown that there is a region near the peripheral part of the drop where $T_{\text {III }}$ is high and almost constant, and this region gradually spreads toward the central part as $\theta$ increases. At the same time, $T_{\text {III }}$ in this region decreases because amine accumulated near the periphery is transferred to the inner part and $y_{\mathrm{I}}$ is decreased during the extraction.

\section{Experimental}

W/O emulsions were prepared as follows. $50 \mathrm{~cm}^{3}$ of kerosine containing $5 \mathrm{vol} \%$ of Span 80 (Sorbitan monooleate) was added to an aqueous solution of $\mathrm{HCl}$ of the same volume. This solution was agitated for $15 \mathrm{~min}$ by a vibromixer (Kyoto Electronics, VM02) equipped with a disc, $5 \mathrm{~cm}$ in diameter, which has 12 holes of $4.5 \mathrm{~mm}$ in diameter, and vibrates vertically at 120 cycles $/ \mathrm{s}$ with an amplitude of $3 \mathrm{~mm}$. Then the solution was sonicated by an ultrasonic homogenizer (Nihon Seiki Ltd., US-150, 150W) for $30 \mathrm{~s}$. A batchtype agitated vessel made of Pyrex glass of $9 \mathrm{~cm}$ inner diameter and $14.5 \mathrm{~cm}$ height was used for the extraction experiment. A six-bladed turbine agitator $5 \mathrm{~cm}$ in diameter and $1 \mathrm{~cm}$ in width was used. To prevent the $\mathrm{W} / \mathrm{O}$ emulsion phase, whose density is 0.9 , from remaining at the surface as a layer, four intermediate baffles were equipped between the wall and the center of the vessel as recommended by Nagata ${ }^{8)}$. The experimental procedure was as follows. $100 \mathrm{ml}$ of the $\mathrm{W} / \mathrm{O}$ emulsion was added to the vessel containing $550 \mathrm{~m} l$ of deionized water under stirring. In about two minutes, the $\mathrm{W} / \mathrm{O}$ emulsion was dispersed as drops in water. Then an aqueous amine solution was poured into the vessel so that the total volume became $750 \mathrm{~m} l$. Samples were withdrawn, filtered to remove the W/O emulsion drops, and analyzed with an ultraviolet spectrophotometer (Shimadzu UV 200S). Hydrogen ion concentration was measured with a Horiba M-7E $\mathrm{pH}$ meter.

dartition coefficients of amines between water and kerosine were measured by shaking the two phases and analyzing the amine concentration in aqueous phase. The diameter of the droplets of the aqueous phase in W/O emulsions was measured by a microscopic method, and the size of W/O emulsion drops by a photographic method. The experimental conditions were as follows: the volume fractions $\phi, \phi^{\prime}$ were 0.5 and 0.1333 , respectively, temperature was $298 \mathrm{~K}$ and the rotational speed was $188 \mathrm{rpm}$.

\section{Results and Discussion}

\section{1 Partition coefficient and diameter of drops}

The measured partition coefficients of amines are

\begin{tabular}{|c|c|c|c|c|}
\hline & \multirow[t]{2}{*}{ Table 1} & \multicolumn{2}{|c|}{ Summary of results } & \multirow[b]{2}{*}{$p$-toluidine } \\
\hline & & Aniline & $m$-toluidine & \\
\hline$K$ & {$[--]$} & 1.1 & 3.7 & 2.8 \\
\hline$p K_{a}$ & & 4.596 & 4.73 & 5.08 \\
\hline$D_{\text {II }} \times 10^{5}$ & {$\left[\mathrm{~cm}^{2} / \mathrm{s}\right]$} & 1.11 & 0.993 & 0.993 \\
\hline$D_{\mathrm{III}} \times 10^{5}$ & {$\left[\mathrm{~cm}^{2} / \mathrm{s}\right]$} & 1.01 & 0.905 & 0.905 \\
\hline$D_{e, e x p} \times 10^{5}$ & {$\left[\mathrm{~cm}^{2} / \mathrm{s}\right]$} & $1.7-2.0$ & $1.4-1.9$ & $1.3-1.5$ \\
\hline$E_{\text {exp }}$ & {$[-]$} & $1.5-1.8$ & $1.4-1.9$ & $1.3-1.5$ \\
\hline$E$ by Eq. (31) & {$[-]$} & 0.43 & 0.43 & 0.43 \\
\hline$E$ by Eq. (32) & {$[-]$} & 4.84 & 4.84 & 4.84 \\
\hline$K_{o} \times 10^{3}$ & {$[\mathrm{~cm} / \mathrm{s}]$} & 4.3 & 4.4 & 4.7 \\
\hline
\end{tabular}

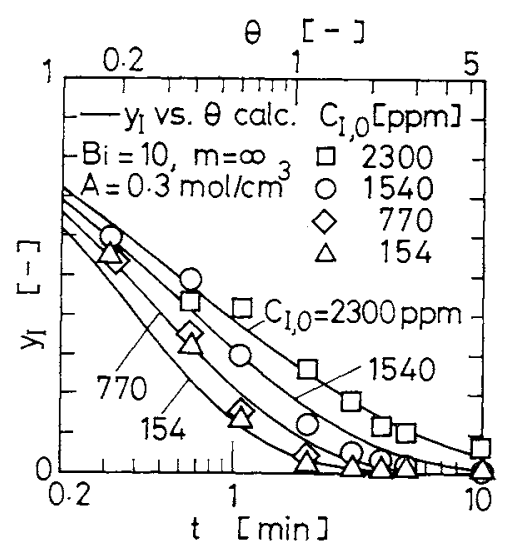

Fig. 7 Effect of $C_{1,0}$ on extraction of aniline

shown in Table 1. Although it was anticipated that some fraction of amine might exist in the form of the dimer in kerosine, the monomer was found to be the predominant species because $K$ was almost independent of amine concentration. Inspection of the W/O emulsion by a microscope showed that the aqueousphase droplet was considerably uniform and the mean diameter was roughly $1 \mu \mathrm{m}$. The size distribution of the W/O emulsion drops was relatively sharp and the average diameter was about $0.9 \mathrm{~mm}$.

\section{2 Breakdown of $W / O$ emulsion}

The breakdown means that phase III droplets leave W/O emulsion drops and enter phase I. The fraction of $\mathrm{HCl}$ which leaks through the membrane is calculated by the following equations.

$$
\begin{gathered}
f=\left[\mathrm{Cl}^{-}\right]_{\mathrm{I}}\left(1-\phi^{\prime}\right) /\left(\left[\mathrm{Cl}^{-}\right]_{\mathrm{IIx}, 0} \phi \phi^{\prime}\right) \\
{\left[\mathrm{Cl}^{-}\right]_{\mathrm{I}}=\left[\mathrm{H}^{+}\right]_{\mathrm{I}}+T_{\mathrm{I}} /\left(1+K_{\alpha} /\left[\mathrm{H}^{+}\right]_{\mathrm{I}}\right)-K_{w} /\left[\mathrm{H}^{+}\right]_{\mathrm{I}}}
\end{gathered}
$$

Equation (28) is derived from Eqs. (1)-(4). The value of $f$ was evaluated from the measured values of $\left[\mathrm{H}^{+}\right]_{1}$ and $T_{\mathrm{I}}$. It was found that $f$ was less than 0.001 at $t=10$ minutes under all experimental conditions, indicating that the membrane was sufficiently stable.

\section{3 Extraction of amines}

1) Effect of initial amine concentration The effect of $C_{\mathrm{T}, 0}$ on the time-course of the extraction of aniline is shown in Fig. 7. Although there is some scatter of the data, it can be seen that when $C_{I, 0}$ is high, $y_{I}$ is also high. To compare the experimental data with 


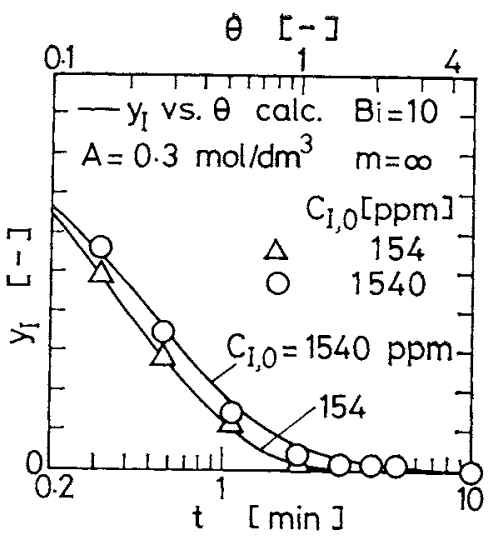

(a) m-toluidine

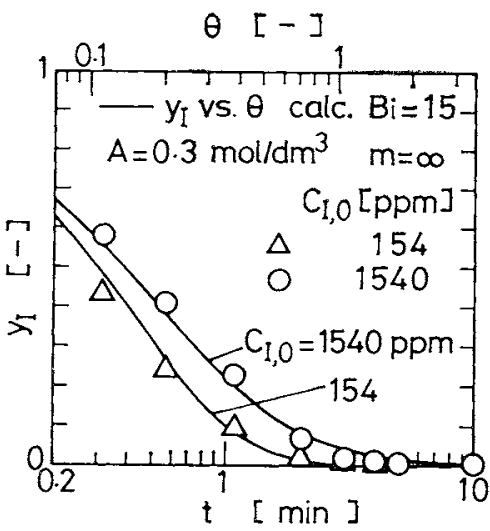

(b) p-toluidine

Fig. 8 Extraction of toluidine

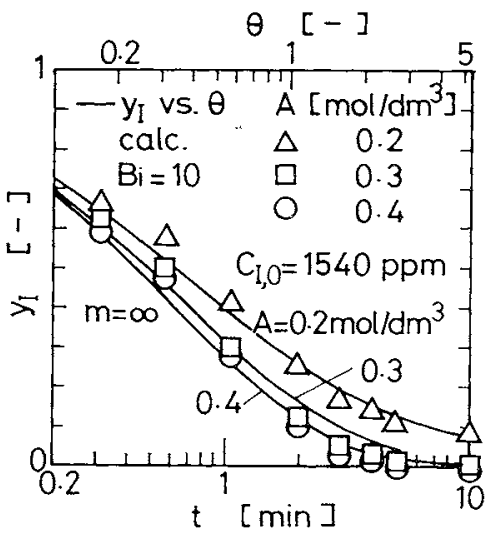

Fig. 9 Effect of $[\mathrm{HCl}]$ on extraction rate of aniline

the computed results based on the present model, it is necessary to estimate seven parameters. Parameters except $B i$ and $m$ are easy to determine. $K_{i}$, which is included in $m$, was estimated as follows. Bacause the diameter of phase III droplets is about $1 \mu \mathrm{m}$ and the droplets may exist in a flocculated structure, the length of diffusion from phase II to III is roughly $1 \mu \mathrm{m}$. If the diffusivity of amine is assumed to be $1 \times 10^{-5} \mathrm{~cm}^{2} / \mathrm{s}$, $K_{i}$ is about $0.1 \mathrm{~cm} / \mathrm{s}$. When the interfacial resistance due to the surface active agent $R_{\mathrm{nnt}}$ is considered, $K_{i}$

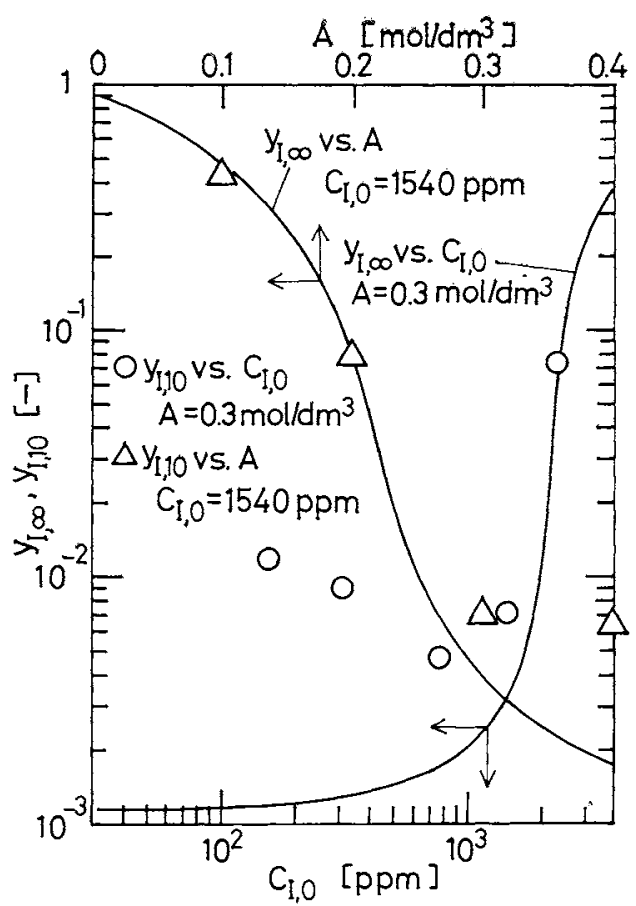

Fig. 10 Comparison between $y_{I, \infty}$ and $y_{1,10}$ (aniline)

may be less than $0.1 \mathrm{~cm} / \mathrm{s}$ although to what extent $K_{i}$ is reduced is not clear. Even if $K_{i}$ is taken as low as $0.01 \mathrm{~cm} / \mathrm{s}, m$ is as large as $10^{5}$. Thus the $y_{\mathrm{I}}$ vs. $\theta$ relation can be approximated by that for $m=\infty$ under the experimental conditions studied. In Fig. 7 are shown the computed results for $m=\infty$ and $B i=10$, which satisfactorily simulate the data. The results of the extraction of $m$ - and $p$-toluidine are shown in Fig. 8, where computed results are also shown.

2) Effect of $\mathrm{HCl}$ concentration As shown in Fig. 9, the effect of $\mathrm{HCl}$ concentration can be well expressed by the present model.

3) Comparison of $y_{I}$ at $t=10 \mathrm{~min}$. with $y_{I, \infty}$ The comparison of $y_{\mathrm{I}, 10}, y_{\mathrm{I}}$ at $t=10 \mathrm{~min}$., with $y_{\mathrm{I}, \infty}$ calculated from Eqs. (25) and (26) is shown in Fig. 10. When $y_{\mathrm{I}, \infty}$ is low, $y_{\mathrm{I}, 10}$ is considerably higher than $y_{\mathrm{I}, \infty}$. On the other hand, $y_{\mathrm{I}, 10}$ is very close to $y_{\mathrm{I}, \infty}$ when $y_{\mathrm{r}, \infty}$ is large. The curves both for $y_{\mathrm{I}, \infty}$ vs. $[\mathrm{HCl}]$ and $y_{\mathrm{I}, \infty}$ vs. $C_{\mathrm{I}, 10}$, which are very similar to the titration curve of the weak base-strong acid system, show that $y_{\mathrm{I}, \infty}$ changes very rapidly with respective concentration at the concentration which is given by the condition of neutralization, i.e., $\left(1-\phi^{\prime}\right) C_{\mathrm{I}, 0}=$ $\phi \phi^{\prime} A$.

4) Evaluation of $D_{e}$ and $K_{o}$ From Figs. 7-9, $t_{\theta=1}$ was calculated, and $D_{e}$ and $K_{0}$ were evaluated by Eqs. (23) and (24). The results are summarized in Table 1. Because the $y_{I}$ vs. $\theta$ relation is considerably influenced by $B i$ as shown in Fig. 5, the accuracy of $t_{\theta=1}$ depends on how definitely $B i$ can be determined by comparing experimental and computed results. However, there 
is actually some range in $B i$ which is thought to give good agreement between them. In addition, because $D_{e}$ is calculated from Eq. (23), the error in measurement of $R$ results in a considerable error in $D_{e}$. Thus, $D_{e}$ 's in Table 1 are considered rough estimates. On the other hand, $K_{o}$ is much less dependent on $B i$ and $R$. For example, when $B i$ is assumed to be $10, D_{e}$ and $K_{0}$ are calculated to be $1.9 \times 10^{-5} \mathrm{~cm}^{2} / \mathrm{s}$ and $0.0043 \mathrm{~cm} / \mathrm{s}$, and when $B i$ is $15, D_{e}$ and $K_{0}$ are $1.4 \times$ $10^{-5}$ and 0.0047 , respectively, based on the experimental data shown in Fig. 7. In Table 1 are also shown the molecular diffusivities of amines estimated by the Wilke-Chang equation ${ }^{11}$. The viscosity of oil phase was measured by an Ostwald viscometer and the average molecular weight was found to be 200 by means of vapor-pressure osmometry. Table 1 shows that $D_{I I}$ is nearly equal to $D_{\text {III }}$, and $D_{e \text { exp }}$ is larger than $D_{\text {II }}$ for each amine. To explain the relation between $D_{e, \exp }$ and $D_{\mathrm{II}}$ or $D_{\mathrm{III}}$, a mass transfer model was developed by modifying Russel's model ${ }^{10\rangle}$ presented for conductive heat transfer through porous media. This model is schematically shown in Fig. 11. A small cube represents a droplet of the internal aqueous phase, and a large cube an element which consists of a droplet of the internal aqueous phase and the membrane which surrounds the droplet. It is assumed that a $\mathrm{W} / \mathrm{O}$ emulsion drop consists of a large number of such elements. Amine can diffuse in this element through two paths. One path is through 1 and 3 (path 1), and another is through 2 and 3 (path 2). If it is assumed that there is no concentration gradient in the direction perpendicular to the radial direction in 3 , the effective diffusivity is given by

$$
E=\frac{D_{e}}{D_{\mathrm{II}}}=\frac{\gamma \phi^{2 / 3}+1-\phi^{2 / 3}}{\gamma\left(\phi^{2 / 3}-\phi\right)+1-\phi^{2 / 3}+\phi}
$$

where $\gamma=D_{\mathrm{III}}^{*} / D_{\mathrm{II}}$, and $D_{\mathrm{II}}^{*}$ is the apparent diffusivity of amine through path 1 in phase III based on the concentration gradient of amine in phase II.

$$
N_{1}=-D_{\mathrm{III}}^{*} \partial C_{\mathrm{II}} / \partial r
$$

Here $N_{1}$ is the flux of total amine in phase III. It should be noted that $D_{I I I}^{*}$ is the apparent diffusivity which is evaluated by considering both the diffusion of amine in phase III in the form of $\mathrm{RNH}_{2}$ as well as $\mathrm{RNH}_{3}{ }^{+}$, and the interfacial resistance, $R_{\text {int }}$, between phases II and III. Because very few data are available on the interfacial resistance due to surface-active agent, it is very difficult to evaluate its contribution to the overall resistance. Here the discussion is made for the two extreme cases. Firstly, $R_{\text {int }}$ due to a surface-active agent for liquid-liquid system was estimated to be about $80 \mathrm{~s} / \mathrm{cm}^{9}$. If $d$ is taken as $1 \mu \mathrm{m}$, the diffusional resistance in phase III, $a / D_{\text {III }}$, is about $8 \mathrm{~s} / \mathrm{cm}$, which is much lower than $R_{\mathrm{int}}$. In this case, $D_{\text {III }}^{*}$ is remarkably decreased due to $R_{\text {int }}$, and $\gamma$ can be

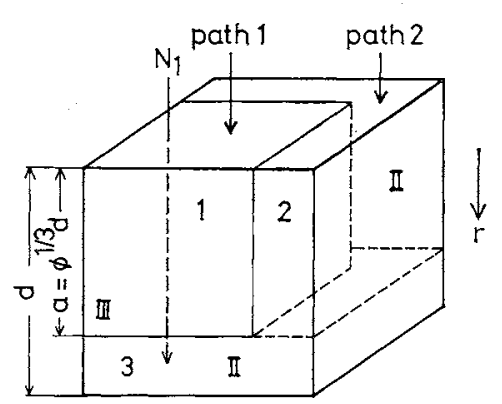

Fig. 11 Mass transfer model in W/O emulsion

approximately taken as zero. Then Eq. (29) reduces to

$$
E=D_{e} / D_{\mathrm{II}}=\left(1-\phi^{2 / 3}\right) /\left(1-\phi^{2 / 3}+\phi\right)
$$

Table 1 indicates that $E_{\exp }$ ranges from 1.3 to 1.9 , and $E$ calculated from Eq. (31) is about one fifth-one third of $E_{\text {exp. }}$. This discrepancy can be explained only when some bulk motion which enhances the diffusion in W/O emulsion drops is assumed.

Secondly, it was reported that addition of a surfaceactive agent does not influence gas absorption rate in a liquid-jet column even when liquid-phase mass transfer coefficient is as large as $0.16 \mathrm{~cm} / \mathrm{s}^{4}$. This suggests that $R_{\text {int }}$ is much lower than $1 / 0.16=6 \mathrm{~cm} / \mathrm{s}$. Then, path 1 in Fig. 11 is not limited by $R_{\text {int }}$. In addition, if we consider that amine can diffuse in phase III in the form of $\mathrm{RNH}_{2}$ as well as $\mathrm{RNH}_{3}{ }^{+}$, and the concentration of $\mathrm{RNH}_{3}{ }^{+}$is much higher than that of $\mathrm{RNH}_{2}$ in region (a) of Fig. 2, the diffusional resistance in phase III may be greatly reduced. In this case, Eq. (32) is derived from Eq. (29) by putting $\gamma$ infinitely large.

$$
E=D_{e} / D_{\mathrm{II}}=1 /\left(1-\phi^{1 / 3}\right)
$$

As shown in Table 1, the value of $E$ by Eq. (32) is about three times the experimentally observed values, which are between those by Eqs. (31) and (32). If $\gamma$ is assumed to be $2.5, E$ by Eq. (29) is 1.6 , which is in rough agreement with $E_{\text {exp }}$. However, further fundamental study on the mass transfer in emulsion systems is needed to discuss $E_{\exp }$ in detail.

As shown in Table $1, K_{o}$ is almost constant irrespective of amines studied. $K_{0}$ is expressed by

$$
1 / K_{o}=1 / k_{w}+1 / K k_{o}
$$

$k_{w}$ was estimated to be $0.0032 \mathrm{~cm} / \mathrm{s}$ using the equation of Calderbank et al. ${ }^{2}$ presented for mass transfer in liquid-liquid dispersions in which the dispersed phases are free to move under the action of gravity. $k_{o}$ is roughly equal to $0.03 \mathrm{~cm} / \mathrm{s}$ if the thickness of a peripheral membrane in a W/O emulsion drop is a few $\mu \mathrm{m}^{7}$. Thus the relation $1 / k_{w} \gg 1 / K k_{0}$ holds, indicating that $K_{o}$ is independent of $K$ in agreement with the experimental data. 


\section{Conclusion}

The extraction of amines was carried out in WO/W/ emulsion systems using a batch-type agitated vessel, and the results were discussed based on a mass transfer model which takes into account the diffusion both in and around a $\mathrm{W} / \mathrm{O}$ emulsion drop. Based on the model of mass transfer in W/O emulsion systems, some explanations were made to interpret the experimentally evaluated values of $D_{e}$.

\section{Nomenclature}

A $=$ concentration of $\mathrm{Cl}^{-}$in phase III

$a_{i} \quad=$ interfacial area between phase II and III per unit volume of W/O emulsion

$a_{o} \quad=$ interfacial area between phase $\mathrm{I}$ and $\mathrm{II}$ per unit volume of $\mathrm{W} / \mathrm{O} / \mathrm{W}$ emulsion

$\mathrm{Bi}=K_{0} R / D_{e}$ (Biot number)

$C \quad=$ concentration of amine $\left(\mathrm{RNH}_{2}\right)$

$\begin{array}{ll}{\left[\mathrm{mol} / \mathrm{m}^{3}\right]} & \text { or }[\mathrm{ppm}] \\ {\left[\mathrm{m}^{2} / \mathrm{s}\right]}\end{array}$

$D_{e} \quad=$ effective diffusivity defined by Eq. (7) $\quad\left[\mathrm{m}^{2} / \mathrm{s}\right]$

$D_{I I I}^{*} \quad=$ apparent diffusivity in phase III defined by Eq. (30)

$d \quad=$ length shown in Fig. $11 \quad$ [m]

$E \quad=D_{e} / D_{11}$

$f \quad=$ fraction of breakdown $\quad[-]$

$K \quad=$ partition coefficient $\quad[-]$

$K_{a} \quad=$ dissociation constant $\quad\left[\mathrm{mol} / \mathrm{m}^{3}\right]$

$K_{i} \quad=$ overall mass transfer coefficient between phase II and III

$[\mathrm{m} / \mathrm{s}]$

$K_{o}=$ overall mass transfer coefficient between phase I and W/O emulsion drop

$K_{w} \quad=$ product of concentrations of $\mathrm{H}^{+}$and $\mathrm{OH}^{-}$

$[\mathrm{m} / \mathrm{s}]$

$k_{0} \quad=$ mass transfer coefficient of peripheral membrane of W/O emulsion

$\left[\mathrm{mol}^{2} / \mathrm{m}^{6}\right]$

$=$ mass transfer coefficient of phase I around $\mathrm{W} / \mathrm{O}$ emulsion drop

$=3 K_{i} R^{2} / R_{i} D_{e}$

$=$ molar flux

$=$ concentration of $\mathrm{RNH}_{3}{ }^{+}$

$=$ radius of $\mathrm{W} / \mathrm{O}$ emulsion $\mathrm{drop}$

$\left[\mathrm{mol} / \mathrm{m}^{2} \cdot \mathrm{s}\right]$ $\left[\mathrm{mol} / \mathrm{m}^{3}\right]$
$R_{i} \quad=$ radius of phase III droplet $\quad[\mathrm{m}]$

$R_{\text {int }} \quad=$ interfacial mass transfer resistance $\quad[\mathrm{s} / \mathrm{m}]$

$r \quad=$ radial distance $\quad[\mathrm{m}]$

$T \quad=$ total concentration of amine $(=C+P)$

$\left[\mathrm{mol} / \mathrm{m}^{3}\right]$

$t \quad=$ time $\quad[\mathrm{s}]$

$x \quad=r / R \quad[-]$

$y_{\mathrm{I}} \quad=C_{\mathrm{I}} / C_{\mathrm{I}, 0}$

$y_{\mathrm{II}} \quad=C_{\mathrm{II}} / K C_{\mathrm{I}, 0}$

$y_{\mathrm{III}}=C_{\mathrm{III}} / C_{\mathrm{I}, 0}$

$\alpha \quad=K_{a} / C_{\mathrm{I}, 0}$

$\beta \quad=A / C_{\mathrm{I}, 0}$

$\gamma \quad=D_{\mathrm{IIJ}}^{*} / D_{\mathrm{II}}$

$\phi \quad=$ volume fraction of phase III in W/O emulsion

$[-]$

$=$ volume fraction of $\mathrm{W} / \mathrm{O}$ emulsion in $\mathrm{W} / \mathrm{O} / \mathrm{W}$ emulsion

$=D_{e} t / R^{2}$

$[-]$

$[-]$

〈Subscripts〉

$0 \quad=$ initial value

I $\quad=$ phase I (external aqueous phase)

II $\quad=$ phase II (organic membrane phase)

III $=$ phase III (internal aqueous phase)

\section{Literature Cited}

1) Cahn, R. P. and N. N. Li: "New Developments in Separation Methods", ed. by E. Grushka, p. 13, Marcel Dekkar Inc., New York (1976).

2) Calderbank, P. H. and M. B. Moo-Young: Chem. Eng. Sci., 16, 39 (1961).

3) Casamatta, G., C. Chavarie and H. Angelino: AIChE J., 24, 945 (1978).

4) Hikita, H., S. Asai and T. Tsuji: ibid., 23, 538 (1977).

5) “Kagaku Benran Kisohen II", p. 996, Maruzen, Tokyo (1975).

6) Li, N. N.: U. S. Patent 3,410,794 (November 12, 1968).

7) Li, N. N. and A. L. Shrier: "Recent Developments in [m/s] Separation Science", Vol. 1, p. 163, CRC Press, Cleveland (1972).

$\begin{array}{rll}{[\mathrm{m} / \mathrm{s}]} & 8) & \text { Nagata, S.: "Mixing", p. 298, Kodansha, Tokyo (1975). } \\ {[-]} & 9) & \text { Quinn, J. A. and P. G. Jeanin: Chem. Eng. Sci., 15, } 243\end{array}$ (1961).

10) Russel, H. W.: J. Am. Ceram. Soc., 18, 1 (1954).

11) Wilke, C. R. and P. Chang: AIChE J., 1, 264 (1955). 